\title{
Gambaran BMI dan Tekanan Darah pada Penderita Tuberkulosis dan Non Tuberkulosis di Desa Pangalengan
}

\author{
Maretha Puspa Nuraili, ${ }^{1}$ Titik Respati, ${ }^{2}$ Engkun Sopian ${ }^{3}$ \\ ${ }^{1}$ Program Studi Pendidikan Dokter, ${ }^{2}$ Bagian Ilmu Kesehatan Masyarakat \\ Fakultas Kedokteran Universtas Islan Bandung \\ ${ }^{3}$ Kepala Puskesmas Pangalengan, Kecamatan Pangalengan, Kabupaten Bandung
}

\begin{abstract}
Abstrak
Tuberkulosis masih menjadi penyakit infeksi menular yang paling berbahaya di dunia. Indonesia menjadi negara dengan jumlah kasus tuberkulosis terbanyak di dunia. Indonesia menempati peringkat kedua bersama Tiongkok. Tuberkulosis suatu penyakit menular yang disebabkan oleh kuman Mycobacterium tuberculosis. Proses terjadinya infeksi oleh Mycobacterium tuberculosis biasanya terjadi secara inhalasi. Penularan penyakit ini sebagian besar melalui inhalasi basil yang mengandung droplet nuclei. Penelitian bertujuan mengetahui gambaran BMI dan tekanan darah pada penderita tuberkulosis dan non tuberkulosis. Penelitian ini dilaksanakan di Desa Pangalengan selama Maret 2020 menggunakan metode deskriptif dengan desain studi cross sectional. Data BMI dan tekanan darah pada pasien tuberkulosis dan non tuberkulosis diperoleh dari survey di Desa Pangalengan sebanyak 210 responden dengan teknik purposive sampling. Hasil penelitian ini menunjukkan bahwa terdapat perubahan BMI pada pasien tuberkulos yang telah menyelesaikan pengobatan serta tidak ada perubahan pada tekanan darah terhadap pasien tuberkulosis.
\end{abstract}

Kata kunci: BMI, tekanan darah, tuberkulosis

\section{Overview of BMI and Blood Pressure in Patients with Tuberculosis and Non Tuberculosis in Pangalengan Village}

\begin{abstract}
Abstrack
Tuberculosis is still the most dangerous infectious disease in the world. Indonesia became the country with the highest number of tuberculosis cases in the world. Indonesia ranks second with China. Tuberculosis disease is a contagious disease caused by gercobacterium tuberculosis. The process of infection by Mycobacterium tuberculosis usually occurs inhaled. The transmission of this disease is largely through the inhalation of basil, which contains droplet nuclei. This research aims to determine the description of BMI and blood pressure in patients with tuberculosis and Non tuberculosis. The study was conducted in

pangalengan Village during March 2020 used a descriptive method with a cross sectional study design. BMI and blood pressure Data in tuberculosis and Non-tuberculosis patients was obtained from a survey in Pangalengan village as many as 210 respondents with sample purposive sampling technique. The results showed that there was a BMI change in the patients who had completed the treatment and no changes in blood pressure to tuberculosis patients.
\end{abstract}

Keywords: BMI, blood pressure, tuberculosis

Received: 14 July 2020; Revised: 25 July 2020; Accepted: 30 July 2020; Published: 31 July 2020

Koresponden: Maretha Puspa Nuraili. Program Pendidikan Profesi Dokter, Fakultas Kedokteran, Universitas Islam Bandung, Jl. Tamansari No. 22, Kota Bandung, Provinsi Jawa Barat. Telepon (o22) 4203368 Hp:081221323424 


\section{Pendahuluan}

Fasilitas pelayanan kesehatan merupakan salah satu faktor yang memengaruhi status derajat kesehatan masyarakat atau perorangan. Tersedianya sarana pelayanan kesehatan yang berkualitas merupakan salah satu upaya pembangunan di bidang kesehatan. Puskesmas adalah fasilitas pelayanan kesehatan yang menyelenggarakan upaya kesehatan masyarakat dan upaya kesehatan perorangan tingkat pertama, dengan lebih mengutamakan upaya promotif dan preventif untuk mencapai derajat kesehatan masyarakat yang setinggi-tingginya di wilayah kerjanya. Harapan seseorang ketika mengunjungi pelayanan kesehatan adalah mendapat pelayanan yang baik, bermutu, dan memuaskan. ${ }^{1}$

Hingga saat ini tuberkulosis masih menjadi penyakit infeksi menular yang paling berbahaya di dunia. Indonesia menjadi negara dengan jumlah kasus tuberkulosis terbanyak di dunia. Tuberkulosis (TB) paru adalah salah satu penyait infeksi kronik yang sudah sangat lama dikenal manusia, misalnya dihubungkan dengan tempat tinggal di daerah urban, lingkungan padat. $^{2}$ Tuberkulosis suatu penyakit menular yang disebabkan oleh kuman Mycobacterium tuberculosis. ${ }^{3}$ Proses terjadi infeksi oleh Mycobacterium tuberculosis biasanya terjadi secara inhalasi. Penularan penyakit ini sebagian besar melalui inhalasi basil yang mengandung droplet nuclei. Hingga saat ini, tuberkulosis masih menjadi penyakit infeksi menular yang paling berbahaya di dunia. ${ }^{3}$

WHO (World Health Organization) melaporkan pada tahun 2016 diperkirakan terdapat 10,4 juta kasus tuberkulosis atau 142 kasus/1.00o populasi, dengan 480.000 kasus multidrug resistant. Berdasar atas Global Tuberculosis Report 2015 yang dirilis oleh WHO, sebanyak 15\% kasus TB baru terjadi di Asia Tenggara dan wilayah Western Pasific pada tahun 2014, India, Indonesia, dan Tiongkok menjadi negara dengan jumlah kasus TB terbanyak di dunia, masingmasing 23\%, 10\%, dan 10\% dari total kejadian seluruh dunia. Indonesia menempati urutan kedua bersama Tiongkok. Satu juta kasus per tahun diperkirakan terjadi di Indonesia (WHO 2015). Sebagian besar estimasi insidensi TB terjadi pada tahun 2016 di kawasan Asia Tenggara (45\%) dan Indonesia merupakan salah satu di dalamnya dan 25\%-nya terjadi di kawasan Afrika. Jumlah kasus baru TB di Indonesia sebanyak 420.994 kasus pada tahun 2017. Berdasar atas jenis kelamin jumlah kasus TB tahun 2017 pada laki-laki 1,4 kali lebih besar dibanding dengan perempuan. Berdasar atas survei prevalensi TB tahun 2013-2014, prevalensi TB terkonfirmasi bakteriologis di Indonesia sebesar 759 per 100.000 penduduk berusia 15 tahun ke atas dan prevalensi TB positif sebesar 257 per 100.000 penduduk berusia 15 tahun ke atas. ${ }^{4}$

Gejala klinis pada TB adalah demam subfebril, batuk/batuk darah, sesak napas, nyeri dada, malaise. Gejala malaise sering di temukan berupa penurunan nafsu makan, badan makin kurus, sakit kepala, meriang, nyeri otot, keringat malam hari. ${ }^{2}$ Salah satu upaya utama penangan kasus tuberkulosis adalah bagaimana memotivasi penderita agar mereka mau menyelesaikan pengobatan sesuai dengan waktu yang telah di tetapkan. Motivasi dan kesadaran yang kurang ini dapat terjadi karena kurangnya pengetahuan dan belum ada sikap yang positif tentang tuberkulosis paru, juga dipengaruhi oleh faktor pelayanan yang kurang memuaskan dari pihak penyelenggara kesehatan, faktor sosio budaya, dan lain-lain. ${ }^{5}$

Perlu dilakukan penilaian dari pasien yang bertujuan melihat gambaran BMI dan tekanan darah terhadap pasien tuberkulosis dan non tuberkulosis sehingga dapat diketahui unsur yang harus diperbaiki oleh puskesmas agar dapat lebih meningkatkan kualitas.

Visi Puskesmas Pangalengan DTP mengadopsi visi Dinas Kesehatan Kabupaten Bandung, yaitu "Terwujudnya Masyarakat Pangalengan yang Sehat dan Mandiri Tahun 2022." Makna dari Visi tersebut adalah bahwa Puskesmas Pangalengan berupaya untuk memberikan pelayanan kepada masyarakat secara PRIMA (profesional adalah memiliki kompetensi dan kemampuan dalam memberikan pelayanan kesehatan yang terbaik sesuai SOP. Responsif adalah cepat tanggap dalam menanggapi masalah kesehatan, Iman dan taqwa adalah menjalankan pelayanan dengan iman dan taqwa, mutu adalah memberikan pelayanan yang berkualitas, amanah adalah dapat dipercaya dalam memberikan pelayanan kesehatan sesuai pedoman dan standar pelayanan yang ditetapkan). Dengan tujuan agar masyarakat di seluruh Kecamatan Pangalengan meningkat derajat kesehatannya secara mandiri di tahun 2022.

\section{Metode}

Penelitian ini menggunakan rancangan penelitian dengan metode deskriptif dengan desain studi cross sectional. Teknik pengambilan data menggunakan survei kepada 210 responden dengan teknik pemilihan purposive sampling. Data yang di gunakan adalah data primer yang diambil dari kuesioner yang disebarkan di Desa Pangalengan Kecamatan Pangalengan, Kabupaten Bandung. Penelitian ini dilakukan pada bulan Maret 2020 untuk mengetahui perbandingan gambaran BMI dan tekanan darah pada penderita tuberkulosis dan non tuberkulosis di Desa Pangalengan tahun 2020 dengan subjek penelitian 210 responden. Instrument, penelitian yang digunakan dalam penelitian ini adalah kuesioner dengan variabel menilai BMI dan tekanan darah terhadap kejadian TB paru di Desa Pangalengan dengan cara mengukur berat badan, tinggi badan, serta tekanan darah pada pasien tuberkulosis dan non tuberkulosis.

\section{Hasil}

Karakteristik responden survei di Desa Pangalengan tahun 2019 dapat dijelaskan pada Tabel 1 menunjukkan data karakteristik responden di Desa Pangalengan. Berdasar atas data menunjukkan mayoritas responden dari keseluruhan adalah perempuan, yaitu sebanyak 113 orang berdasar atas usia mayoritas usia 18-60 tahun sebanyak 183, tingkat pendidikan mayoritas SMP sebanyak 80 orang, dan pekerjaan sebagai wiraswasta sebanyak 66 orang. 
Tabel 1 Karakteristik Responden Survei Desa Pangalengan

\begin{tabular}{lcccc}
\hline \multirow{2}{*}{ Karakteristik } & \multicolumn{2}{c}{ Tuberkulosis } & Non Tuberkulosis \\
\cline { 2 - 5 } & Jumlah & Persen & Jumlah & Persen \\
\hline Jenis kelamin & & & & \\
Laki-laki & 29 & 36,6 & 68 & 52,3 \\
Perempuan & 51 & 63,8 & 62 & 47,7 \\
Usia (tahun) & & & & \\
<18 & 13 & 16,6 & 10 & 7,7 \\
18-60 & 63 & 78,8 & 120 & 92,3 \\
>6o & 4 & $5 \%$ & 0 & 0 \\
& & & & \\
Tingkat & & & & \\
pendidikan & 17 & 21,3 & 37 & 28,5 \\
SD/sederajat & 35 & 43,8 & 45 & 34,7 \\
SMP/sederajat & 21 & 26,6 & 40 & 30,8 \\
SMa/sederajat & 7 & 8,8 & 8 & 6,1 \\
D3/S1 & & & & \\
Pekerjaan & & & & \\
IRT & 25 & 31,3 & 34 & 26,1 \\
Wiraswasta & 24 & 30 & 42 & 32,3 \\
Pelajar & 11 & 13,8 & 11 & 8,5 \\
Guru & 4 & 5 & 3 & 2,3 \\
Buruh & 11 & 13,8 & 26 & 20 \\
Tidak bekerja & 2 & 2,5 & 11 & 8,5 \\
Karyawan & 3 & 3,8 & 2 & 1,5 \\
\hline
\end{tabular}

Tabel 2 Distrtibusi Frekuensi BMI pada Penderita Tuberkulosis dan Non Tuberkulosis di Desa Pangalengan

\begin{tabular}{|c|c|c|c|c|}
\hline \multirow{2}{*}{ BMI } & \multicolumn{2}{|c|}{ Tuberkulosis } & \multicolumn{2}{|c|}{ Non Tuberkulosis } \\
\hline & Jumlah & Persen & Jumlah & Persen \\
\hline $\begin{array}{l}\text { Underweight } \\
<18 \mathrm{~kg} / \mathrm{m}^{2}\end{array}$ & 15 & 18,8 & 6 & 4,6 \\
\hline $\begin{array}{l}\text { Normal } \\
18,5-24,9 \mathrm{~kg} / \mathrm{m}^{2}\end{array}$ & 59 & 73,8 & 97 & 74,6 \\
\hline $\begin{array}{l}\text { Overweight } \\
\geq 25 \mathrm{~kg} / \mathrm{m}^{2}\end{array}$ & 3 & 3,8 & 3 & 2,3 \\
\hline $\begin{array}{l}\text { Pre-obese } \\
25,0-29,9 \mathrm{~kg} / \mathrm{m}^{2}\end{array}$ & 3 & 3,8 & 20 & 15,3 \\
\hline $\begin{array}{l}\text { Obese I } \\
30,0-34,9 \mathrm{~kg} / \mathrm{m}^{2}\end{array}$ & $\mathrm{O}$ & o & 4 & 3,1 \\
\hline $\begin{array}{l}\text { Obese II } \\
35,0-39,9 \mathrm{~kg} / \mathrm{m}^{2}\end{array}$ & $\mathrm{O}$ & $\mathrm{O}$ & $\mathrm{O}$ & $\mathrm{O}$ \\
\hline $\begin{array}{l}\text { Obese III } \\
\geq 40 \mathrm{~kg} / \mathrm{m}^{2}\end{array}$ & o & $\mathrm{O}$ & $\mathrm{o}$ & o \\
\hline
\end{tabular}

Tabel 2 menunjukkan bahwa nilai BMI di Desa Pangalengan paling banyak pada nilai normal dengan penderita tuberkulosis sebanyak 59 orang $(73,8 \%)$, sedangkan non tuberkulosis sebanyak 97 orang (74,6\%).
Tabel 3 Distrtibusi Frekuensi Tekanan Darah pada Penderita Tuberkulosis dan Non Tuberkulosis di Desa Pangalengan

\begin{tabular}{lcccc}
\hline \multirow{2}{*}{$\begin{array}{l}\text { Tekanan Darah } \\
(\mathbf{m m H})\end{array}$} & \multicolumn{2}{c}{ Tuberkulosis } & \multicolumn{2}{c}{ Non Tuberkulosis } \\
\cline { 2 - 5 } Jumlah & Persen & Jumlah & Persen \\
\hline $\begin{array}{l}\text { Normal }<120 /<80 \\
\text { Prehipertensi }\end{array}$ & 64 & 80 & 96 & 73,8 \\
$\begin{array}{l}120-139 / 80-89 \\
\text { Stage I 140- }\end{array}$ & 3 & 3,8 & 3 & 21,6 \\
$\begin{array}{l}\text { 159/90-99 } \\
\begin{array}{l}\text { StageII } \\
\geq 160 / \geq 100\end{array}\end{array}$ & 0 & 0 & 3 & 2,3 \\
\hline
\end{tabular}

Tabel 3 menunjukkan bahwa frekuensi nilai tekanan darah paling banyak pada nilai normal baik pada penderita tuberkulosis maupun non tuberkulosis. pada penderita tuberkulosis sebanyak 64 orang (80\%) sedangkan pada penderita non tuberkulosis sebanyak 96 orang $(73,8 \%)$.

\section{Pembahasan}

Berdasar atas hasil penelitian di atas mengenai BMI pada pasien tuberkulosis dengan berat badan underweight 15 orang (18,8\%), normal 59 orang $(73,8 \%)$, overweight 3 orang $(3,8 \%)$, dan pre-obese 3 orang $(3,8 \%)$. Pada pasien non tuberkulosis didapatkan berat badan underweight 6 orang (4,6\%), normal 97 orang $(74,6 \%)$, overweight 3 orang $(2,3 \%)$, dan preobese 20 orang $(15,3 \%)$.

Berdasar atas karakteristik tekanan darah pada pasien Tuberkulosis yang memiliki tekanan darah normal sebanyak 64 orang (80\%), prehipertensi 13 orang (16,3\%), hipertensi stage 1 sebanyak 3 orang $(3,8 \%)$. Pada penderita non tuberkulosis didapatkan tekanan darah normal 96 orang $(73,8 \%)$, prehipertensi 28 orang $(21,6 \%)$, hipetensi stage 1 sebanyak 3 orang $(2,3 \%)$ dan hipertensi stage 2 sebanyak 3 orang $(2,3 \%)$. Hasil penelitian di atas ada perubahan kenaikan berat badan setelah penderita menjalani pengobatan. Tidak ada perubahan tekanan darah pada saat pasien menderita tuberkulosis. Hal ini sesuai dengan penelitian yang dilakukan peneliti lain tahun 2011 bahwa terdapat perubahan BMI ketika pasien telah melakukan pengobatan tuberkulosis serta tidak ada hubungan tekanan darah dengan penyakit tuberkulosis. Pada penelitian tersebut dinyatakan tekanan darah meningkat apabila terdapat penyakit penyerta $^{6}$

Hasil penelitian ini juga sesuai dengan penelitian Fadhalna dkk.7 tahun 2017 yang menyatakan bahwa pada pasien tuberkulosis yang telah menyelesaikan pengobatan terdapat peningkatan BMI. Fadhalna dkk.7 juga menyatakan dari penelitian yang telah dilakukan hampir semua responden mencapai BMI normal. Penelitian yang dilakukan Lombardo dkk. ${ }^{8}$ tahun 2012 pada tuberkulosis yang masih mengalami underweight setelah menjalani pengobatan hingga selesai menyatakan bahwa asupan suplementasi zinc dan vitamin A itu kurang terutama pada penderita tuberkulosis. Oleh karena itu, suplementasi zinc dan 
vitamin A apabila diberikan bersama-sama dengan pengobatan tuberkulosis, mungkin bermanfaat dalam meningkatkan hasil pengobatan penderita yang sudah malnutrisi setelah 2 bulan terapi. ${ }^{8}$ Penelitian lain dinyatakan pada penderita yang mengalamioverweight dan preobesitas kemungkinan reinfeksi tuberkulosis dapat terjadi apabila BMI yang berlebihan menjurus ke arah penyakit metabolik yang dapat meningkatkan risiko infeksi tuberkulosis seperti diabetes melitus.

\section{Simpulan}

Simpulan penelitian ini adalah sebagian besar nilai BMI dan tekanan darah pada pasien tuberkulosis maupun non tuberkulosis baik.

\section{Ucapan Terima Kasih}

Ucapan terimaksih penulis sampaikan kepada pembimbing stase Ilmu Kesehatan Masyarakat (IKM) kami, seluruh staf Puskesmas Pangalengan DTP dan warga Desa Pangalengan yang telah terlibat dalam penelitian ini.

\section{Daftar Pustaka}

1. Kemenkes RI. Buku Data Dasar Puskesmas Kondisi Desember 2015. Jakarta: Pusat Data Kemkes RI; 2016.
2. Sudoyo AW, Setiyohadi B, Alwi I, Simadibrata M, Setiadi S. Buku ajar ilmu penyakit dalam Jilid 2. Interna Publishing. Jakarta: Pusat Penerbitan Departemen Ilmu Penyakit Dalam; 2007.

3. Pengantar K. Anti-tuberculosis. Curr Bioact Compd. 2012;2(1):105.

4. Afifah I. Peningkatan kapasitas angggota couple community dalam meningkatkan support group untuk mendukung Sufa Konsumsi ARV setiap hari tingkatkan kualitas hidup ODHA. Surabaya: Dinas Kesehatan Surabaya; 2015.

5. Nurkomarasi N, Respati T, Budiman B. Karakteristik penderita drop out pengeobatan tuberkulosis paru di Garut. GMHC. 2014;2:21-6.

6. Tsani RM. Gambaran klinis tuberkulosis paru di RSUP Dr . Kariadi Semarang periode Januari-Juni 2011. J Kesehat Muhammadiyah. 2012;1(2):33-9.

7. Fadhalna, Ihwan, Swastika IN. Gambaran indeks massa tubuh penderita tuberkulosis paru positif yang melakukan pengobatan di Gerdunas TB Rumah Sakit Untada Palu Sulawesi Tengah. Biocelebes. 2017;11(1):9-12.

8. Lombardo CC, Swart R, Visser ME. The nutritional status of patients with tuberculosis in comparison with tuberculosis-free contacts in Delft Western Cape. South African J Clin Nutr. 2012;25(4):1801. 